\title{
COVID-19 as Viewed by The Pathologist: A Rapid Literature Review
}

\author{
Francesco Callea, MD. PhD.
}

Department of Pathology and Molecular Histopathology, Catholic University and Bugando Medical Centre, Mwanza, Tanzania.

\begin{abstract}
The current coronavirus outbreak represents a severe threat to public health worldwide. Finding measures to properly manage and prevent the epidemic is ongoing, right now practitioners and public health authorities need immediate, actionable information. Basic science and medical scientific disciplines have quickly produced a quantity of publications never seen with other emergencies, with a risk of exaggerated information and non-evidence-based measures.

This rapid literature review of PubMed ${ }^{\oplus}$ MEDLINE publications from January 20 to April 20, 2020 using COVID-19 as main key-word resulted in over 6.000 articles, with around 600 reviews. The contributions were subsequently clustered in subgroups according to journal sources and preselected areas of reference.

Results were aggregated into 4 categories: supported, promising controversial and critical data.

This Review has revealed a major criticality: only seven pathology articles were based on post-mortem material (minimally invasive autopsies/biopsies). Dealing with an unknown disease, autopsies are indispensable to understand pathogenetic mechanisms, in order to rationalize therapeutic interventions. Even more important is to adopt a dedicated protocol aimed at correlating pathological findings with disease duration, patient location (home, hospital ward, ICU), and, for each period, symptoms, and treatment. Autopsy reports should not be released before a multidisciplinary discussion by hospital Root Cause Analysis or Morbidity/Mortality conferences. Telepathology is not a suitable means for such studies.
\end{abstract}

\section{KEYWORDS}

COVID-19, Rapid literature review, Pathology.

Correspondins Author Information

Francesco Callea

Francesco Callea MD PhD, Professor of Pathology, Catholic University Bugando Medical Centre of Mwanza, P.O. Box 1464, Mwanza, Tanzania, Tel: +39-3355349730.

Received: June 04, 2020; Accepted: July 17, 2020; Published: July 21, 2020

Copyright: (C) 2020 ASRJS. This is an openaccess article distributed under the terms of the Creative Commons Attribution 4.0 International license.

Citation: Francesco Callea. COVID-19 as Viewed by the Pathologist: A Rapid Literature Review. Med Clin Res Open Access, 2020;1:1-7.

\section{Introduction}

The 2019-nCoV (COVID-19) pandemic is a world emergency alerting global health institutions. Effective management and prevention of epidemics takes time, but practitioners and public health authorities (PHAs) still need precise, scientific data and actionable information.
The New England Journal of Medicine published an editorial [1], encouraging scientists to share important information with PHAs as early as possible and created links to essential resources for clinicians, an editorial policy shared by other journals (www. NEJM.org/coronavirus). This pandemic has resulted in many publications, reducing submission-acceptance-publication times up to 2-10 days. This proliferation of articles has generated some 
harmfully exaggerated information and non-evidence-based measures [2,3], but has also spawned an impressive number of review articles in record time.

The present rapid literature review (RLR) aims to extrapolate, and critically assess useful and controversial data from scientific articles on COVID-19.

Widespread knowledge of COVID-19 has been traced to December 30, 2019, urgent PreMED (International Society for Infectious Diseases, http://www.isid.org) communication by the Wuhan Medical Health Committee about a pneumonia of unknown origin. On December 31, a more detailed notice was adding that a series of patients from the South China Seafood Market in Wuhan had exhibited the same pneumonia [4]. On January 8, 2020, a coronavirus was isolated and recognized as the causative agent of the pneumonias [5]. The genome sequence was made publicly available to the scientific community [6], showing that SARS$\mathrm{CoV}-2$ belongs to the $\beta$-coronavirus genus, with $79.0 \%$ nucleotide identity to SARS-CoV and $51.8 \%$ identity to MERS-CoV. Soon after, it was reported that the $\mathrm{nCoV}-19$ is $96 \%$ identical across the entire genome to a bat coronavirus [7].

This information immediately resuscitated the neglected debate following the characterization of a chimeric virus produced in laboratory, expressing the spikes of a bat coronavirus SHCO14 in a mouse adapted SARS-CoV backbone in 2015 [8]. As the bat SARS-like coronavirus was shown to use Angiotensin Converting Enzyme (ACE2) receptors to enter the target cells similar to the nCoV-19 [9], it was suggested that the bat coronavirus could have potential for human emergence [8].

The $2019 \mathrm{nCoV}$, renamed COVID-19, rapidly spread from Wuhan to the Hubei region and soon after outside China, involving all countries of the world. On March 11, 2020, the WHO has declared the COVID-19 outbreak a pandemic, which has caused more than 4 million infections and over 300,000 deaths.

\section{Study Methodology}

Various methods for RLR have been developed [10], with modifications adopted to increase the speed and focus compared to full systematic reviews [11]. The RLR herein further simplifies the methodology, considering the global emergency and short time period. Moreover, only one reviewer conducted the study selection and data extraction [10]. The RLR was conducted in three steps: developmental (strategy, question and inclusion criteria), processing (screening of titles, abstracts, and full text articles selected for retrieval - including hand searches of reference lists, data extraction), and reporting of results. The literature search was conducted via PubMedR/MEDLINE using keywords: main term: COVID-19; time limits: January 20-April 20, 2020; language: English and Asian with English abstract, journals and topics per Journals selected according to main aim of the study.

Evidence was ranked to provide a simple overall picture of the state of the literature. Considering strength of evidence, direction of findings, consistency, generalizability and applicability, and total body of evidence for intervention questions, appropriateness of ranking resulted into four categories: a) supported, b) promising, c) controversial, d) critical data.

\section{Results}

The PubMed search resulted in 6122 papers, including 619 reviews. Articles were clustered according to journal source and mission/ competence, totaling 383 journals, topics and topics per Journal. Publications dealing with histopathological observations are summarized in Table 1.

Given the lack of knowledge on COVID-19, its virulence, spreading and pathogenicity, analysis of publications focused mainly on selecting data of potential use for disease management and adjunctive countermeasures in diagnosis and treatment, according to the emerging body of evidence, classifying results into four groups:

Supported data present in articles [12] and reviews [13]:

- SARS-CoV-2 is a new coronavirus affecting any age with most severe course in elderly, medically compromised and more vulnerable people.

- In children and healthy adults, the infection runs an asymptomatic or mild course.

- Early symptoms can be non-specific (flu-like syndrome) or rather specific (anosmia/ dysgeusia).

- Lung involvement results in an interstitial pneumonia.

- Major complications include cytokine storm and coagulation problems (thrombotic microangiopathy, thromboembolism, disseminated intravascular coagulation -DIC-).

- Respiratory failure, heart failure and coagulopathies are the causes of death.

- Other organs may be affected: CNS, GI tract, cardiovascular and urinary systems skin, and skeletal muscle.

- Virus transmission is human-to-human mostly via aerosol, but also possible via saliva, urine, tears, and feces.

- Structure and epidemiology of the virus.

- Diagnostic tools.

- No specific treatment is available.

Promising data

Promising data refer to the mechanisms of virus-host cell interaction representing the preliminary requirements for prevention and treatment.

Chymotrypsin-like protease (CLP) inhibitors of SARS-COVID-2 have been identified [14]. Remdesevir seems capable of inhibiting CLP function [15]. Based on knowledge of the mechanism of cell attack by $\mathrm{CoV}-2$, monoclonal antibodies are being produced [16]. Recovered COVID-19 patients raised IgM and IgG antibodies [17]. Thus, passive immunization with fresh plasma from convalescent or recovered patients is being attempted [18]. Circulating specific IgM and IgG antibodies are being tested to establish neutralizing capability and titers over time. 
Table 1. COVID-19 published histopathological papers.

\begin{tabular}{|c|c|c|c|c|c|}
\hline Authors & Cases $\mathbf{N}^{*}$ & Autopsy & Specimens & Postmortem biopsy & Histopathological lesions \\
\hline \multirow{2}{*}{$\begin{array}{l}\text { Barton LM, et al. } \\
\text { Am J Clin Pathol }\end{array}$} & $\mathrm{M}^{\circ}: 77$ years & Yes (Partial) & Lung & - & $\begin{array}{l}\text { Diffuse alveolar damage (DAD) } \\
\text { Patchy interstitial inflammation } \\
\text { Thrombi in small arteries }\end{array}$ \\
\hline & M: 42 years & Yes (complete) & Lung and heart & - & $\begin{array}{c}\text { No DAD } \\
\text { Aspiration and bacterial pneu- } \\
\text { monia }\end{array}$ \\
\hline $\begin{array}{c}\text { Xu Z, et al. } \\
\text { Lancet Resp Med }\end{array}$ & M: 50 years & - & Lung, heart, liver & Yes & $\begin{array}{l}\text { DAD, multinucleate giant cells } \\
\text { Interstitial inflammation, cyto- } \\
\text { pathic changes }\end{array}$ \\
\hline \multirow{4}{*}{$\begin{array}{c}\text { Tian S, et al. } \\
\text { Modern Pathology }\end{array}$} & M: 59 years & - & Lung, heart, liver & Yes & \multirow{4}{*}{$\begin{array}{l}\text { DAD, small vessel thrombi } \\
\text { Bacterial superinfection } \\
\text { Non-specific reactive hepatitis } \\
\text { Heart: focal fibrosis }\end{array}$} \\
\hline & M: 74 years & & Lung, heart, liver & Yes & \\
\hline & M: 78 years & & Lung, heart, liver & Yes & \\
\hline & M: 81 years & & Lung, heart, liver & Yes & \\
\hline $\begin{array}{l}\text { Karami P, et al. } \\
\text { Travel Med Infect Dis }\end{array}$ & M: 27 years & Yes (partial) & Lung & - & DAD + cytopathic damage \\
\hline $\begin{array}{c}\mathrm{Su} \mathrm{H} \text {, et al. } \\
\text { Kidney International }\end{array}$ & $\begin{array}{l}26 \text { patients: } \\
19 \text { F\# \& } 7 \mathrm{M} \text {; mean } \\
\text { age } 69 \text { years }\end{array}$ & - & Kidney & Yes, all patients & $\begin{array}{l}\text { Diffuse proximal tubule damage } \\
\text { and necrosis; electron microscopy } \\
(\mathrm{EM}) \text { : presence of viral particles }\end{array}$ \\
\hline $\begin{array}{c}\text { Yao XH et al. Zhong- } \\
\text { hua B L X }\end{array}$ & $3 \mathrm{M}$ patients & $\begin{array}{l}\text { Minimally } \\
\text { invasive }\end{array}$ & $\begin{array}{l}\text { lung, heart, intes- } \\
\text { tine, skin, liver, Bone } \\
\text { marrow, kidney }\end{array}$ & & $\begin{array}{l}\text { DAD, minimal inflammation, } \\
\text { small vessel thrombi, multinucle- } \\
\text { ate giant cells, }\end{array}$ \\
\hline $\begin{array}{l}\text { Tian S, et al. } \\
\text { J Thorac Oncol }\end{array}$ & $2 \mathrm{M}$ patients & Surgery & Lung & & $\begin{array}{l}\text { Edema, patchy inflammation, } \\
\text { pneumocyte hyperplasia, multinu- } \\
\text { cleated giant cells }\end{array}$ \\
\hline
\end{tabular}

Table 2. Relevant information on patient's history for autopsy finding correlation.

\begin{tabular}{|c|c|c|c|c|c|c|c|c|c|c|c|c|}
\hline Stay & $\begin{array}{c}\text { Duration } \\
\text { (days) }\end{array}$ & Symptoms & $\begin{array}{l}\text { Coagula- } \\
\text { tion tests }\end{array}$ & $\begin{array}{l}\text { Inflam- } \\
\text { matory } \\
\text { screening }\end{array}$ & $\begin{array}{l}\text { Treatment } \\
\text { (type and } \\
\text { duration) }\end{array}$ & $\begin{array}{l}\text { Treatment } \\
\text { (assess- } \\
\text { ment of } \\
\text { efficacy) }\end{array}$ & $\begin{array}{c}\text { Cov-2 } \\
\text { RT-PCR }\end{array}$ & IgA & IgM & IgG & $\begin{array}{l}\text { Known } \\
\text { comorbid- } \\
\text { ities }\end{array}$ & $\begin{array}{c}\text { Death } \\
\text { diagnosis }\end{array}$ \\
\hline
\end{tabular}

Home

Hospital

ICU

A.

Autopsy reporting protocol (proposal)

Post-mortem findings:

i. Macroscopy

ii. Microscopy

B.

Preexisting pathology

C.

D.

Acute pathology (COVID-19 related lesions)

Pathomorphogenesis of the lesions

E. Mechanism of death

F. Multidisciplinary conferences (RCA and M/M) for clinical-pathological correlation (lesions-symptoms and vice-versa)

G. $\quad$ Epicrisis (including timing of the lesions)

H. Needs for further pathological and virological investigations, including ancillary techniques 
Controversial data

- Origin of SARS-CoV-2

- Radiological findings

- Treatment and mechanism of action of non-specific drugs

- Role of SARS-CoV-2 in triggering organ pathology

Coronaviruses are zoonotic viruses that can infect both humans and various animals $[9,10]$. The human SARS-CoV-2 seems to have derived from the homologous strain from bat [19] and is genetically distinct from SARS-CoV and SARS-MERS, whose intermediate hosts were masked palm civets and camel, respectively. The SARS-CoV-2 appears to be a recombinant virus between the bat coronavirus and an origin-unknown coronavirus [19]. Furthermore, SARS-CoV-2 has most similar codon usage bias with snake. Altogether, these observations suggest that homologous recombination may occur and contribute to SARS$\mathrm{CoV}$ cross-species transmission [20]. It remains unclear whether an intermediate host, such as snake, cat, dog sold in Wuhan seafood market, was involved before the virus jumped to humans [21].

These phenomena suggest that new coronavirus epidemics could easily reappear. Additionally, the possibility that physics or atmospheric agents, as well as genetic engineering, might produce mutations cannot be ruled out.

COVID-19 presented originally as a severe pneumonia of unknown cause [3].

Chest radiographic (CXRs) and CTs findings [22], and ground glass opacity have emphasized consolidation as consistent features for interstitial pneumonia. Interpretation of lung imaging and clinical deterioration have led to extensive use of mechanical ventilators in Intensive Care Units (ICUs). Following the emergence of severe complications, such as thrombotic microangiopathy, venous thromboembolism and DIC, interpretation of imaging has been revised with CT pulmonary angiography instead of non-contrast chest CTs [23] and adjusted to patient management [24].

No specific treatment and no approved specific antivirals for COVID-19 are available to-date. Therefore, multiple drugs, mostly in combination, are being empirically employed.

Chloroquine, an antimalarial drug known for its anti-inflammatory and antiviral effects, widely used in autoimmune disorders, has shown encouraging results [25]. Better results have been reported with HCQ combined with Azithromycin [26], or HCQ and Remdesevir [27]. Moreover, some potential antiviral agents have been administered with controversial or unsatisfactory results [28].

In addition, two main detrimental processes have been recognized: cytokine storm and coagulation disturbances. Cytokine storm plays a major role in worsening the inflammatory process in COVID-19 pneumonia. Tocilizumab seems to slow down inflammation due to its anti-interleukin-6 and immunomodulation action [29]. Coagulation disturbances can be prevented or cured by anticoagulants (low molecular weight heparins - LMWH) [30].
The role of SARS-CoV-2 in triggering organ or systemic pathology is due to the capacity of spike proteins to bind ACE2 receptors expressed in a number of epithelial cells [31] and to cause cytotoxic effect, symptoms and further spread of contagion. The major cell targets are type II pneumocytes, enterocytes, renal tubular cells, myocardial capillary pericytes and endothelial cells. The expression of ACE 2 receptors is highly increased in patients with basic cardiovascular disease. The pericyte injury due to virus infection may result in capillary endothelial cell dysfunction, inducing microvascular dysfunction [32]. The oral cavity contains plenty of ACE2 receptors, thus explaining why contagion can spread through saliva.

Authors have reported $\mathrm{nCoV}$ particles on EM in endothelial cells [33] and in renal tubular cells [34], but the latter finding has not been confirmed [35].

Pathogenesis of the coagulation disorders is not completely understood.

\section{Critical data}

Most unsolved/unanswered questions are attributable to the lack of extensive anatomo-pathological studies. Histopathology represents the main source of information for understanding disease process initiation and progression. This RLR found seven histopathological reports, with surgical [36], post-mortem core biopsies [34,37-39], or minimally invasive autopsies $[40,41]$.

In all publications, sections on Histopathological Results and relative figures were focused mainly on lung: diffuse alveolar damage, foreign body aspiration, hyaline membranes, mixed neutrophillymphocyte-macrophages infiltration, hyperplastic pneumocytes, intra-alveolar shedding, or presence of megakaryocytes, cytopathic cytoplasmic changes of viral antigen containing pneumocytes and macrophages. The description of other organs was very poor or lacking.

Indeed, the section "Histopathological findings" from publications consists of a list of lesions without clinical-pathological correlation or discussion on pathomorphogenesis.

The lack of COVID-19 autopsies and the incomplete reporting of histological findings could depend on: (i) overall decline in numbers of hospital autopsies over the last 50 years [42], (ii) high risk, (iii) oblivion of the basic methodology and importance of post-mortem examination for unknown disease.

In 1978 the NEJM has suggested their revival also for cases with known cause of death [43]. The autopsy reports contain detailed description, interpretation of the lesions, clinical-pathological correlations and epicrisis, thus enormously differing from "Histopathological findings" sections from publications.

A call for action and need for autopsies to determine the full extent of organ involvement was launched on March 16, 2020 [44]. Indeed, with new diseases like COVID-19, extensive tissue studies 
are indispensable to understand the pathomorphogenesis of the lesions, the natural history and their modifications after treatment. This necessity overwhelms any refrain in performing autopsies even in case of pandemic.

\section{Discussion}

This RLR on COVID-19 has revealed an imbalance between scientific effort and resulting knowledge. In the absence of specific drugs and effective vaccine, management and treatment have been necessarily empirical.

Measures to prevent contagion and recognition of symptoms, such as anosmia and dysgeusia, i.e., virtually diagnostic, are important. Respiratory failure can occur rapidly with cough worsening and oxygen desaturation. Imaging investigations may reveal groundglass opacities and patchy consolidation. Further, in disease course, a cytokine storm, coagulation problems, renal and heart failure may develop causing death.

Considering the clinical pathway for early diagnosis and all data from this RLR, a logical management of COVID-19 patients could be envisaged. People presenting early anosmia and dysgeusia [45] should be considered infected and isolated before performing a swab in order to prevent contagion spreading. Further, they should be clinically monitored at home or hospitalized according to symptoms severity.

If flu-like symptoms appear, first line of treatment may consist in using hyperimmune plasma or monoclonal anti-CoV-2 antibodies combined with antivirals, anti-inflammatory and antibiotics, to try preventing disease progression and pulmonary involvement. The confirmation of clinical diagnosis requires nucleic acid testing by RT-PCR. The tests are being performed on oro- and nasopharyngeal swab. However, saliva could be a suitable material for a safe diagnostic purpose [46].

Symptomatic hospitalized people should undergo radiological evaluation (standard $\mathrm{Rx}, \mathrm{CT}$ angiography), and undergo prophylactic anti-interleukin drugs and anticoagulants to prevent or slow down cytokine storm and coagulopathies respectively. IgM and IgG testing are expected to allow for identifying virgin, infected, recovering and short-term or long-term immunized persons.

Given the above, access to ICUs as well as mortality rate should drop. Non-surviving patients should be autopsied with caution due to the hazard level in adequately equipped morgue structures [47].

In a time of pandemic, an instructive model from the XIX century may become again topical. Bypassing the historical rivalry between the famous Koch and Pasteur Institutes, Alexandre Yersin rushed to Hong-Kong to identify the causative agent of the plague epidemic [48].

With regard to the shortage of tissue samples, pathologists are looking to collect specimens by establishing a COVID-19
Pathology Consortium and share results by telepathology in view of a pathology repository.

The results from this RLR have increased the consciousness of urgent understanding of tissue damage mechanisms and pathology progression that is the only means to rapidly proceed to rationalize therapeutical approaches before a vaccine becomes available.

The methodology to perform autopsies by the father of the Modern Pathology, J.B. Morgagni in 1761, again becomes topical, as based on the search for lesion-symptom correspondence and viceversa [49]. That has given anatomic theater the privileged definition of places where "death is pleased to help the living". Obviously Morgagni's principles need to be contextualized within the COVID-19 scenario, according to the requirements of Modern Medicine that, after shattering the walls among the four classic watertight compartments of medicine (research, education, laboratory service and clinical care) has decreted the transition from MD-physician to MD-researcher then to $\mathrm{PhD}$-scientist and the identification of diagnostic and research activity [50].

Relevant clinical information related to disease duration, place and time of the patient's stay (home, hospital ward, ICU), each of them recording symptoms and treatment, coagulation/inflammatory test, host-virus immunological state, comorbidities, clinical diagnosis of death should be evaluated together with histopathological findings (Table 2). Each autopsy report should be discussed within the hospital by multidisciplinary teams by Root Cause Analysis or Morbidity/Mortality conferences [51].

At this stage and for the aim of the study, telepathology is not recommended as a fruitful instrument [52]. It is hoped that the above methodology will increase the knowledge on COVID-19, allowing more logical and effective interventions to prevent/slowdown/treat the disease, and interrupt the cascade of precipitating events.

Indeed, it would seem that COVID-19 is more than (only) a Severe Acute Respiratory Syndrome.

\section{Acknowledgement}

The Author wishes to thank Helen Banks for English language revision, Dr. Marialuisa Corbeddu for editorial assistance, and the Italian No-profit Association Friends Raising ONLUS for supporting the Master in Pathology program in Mwanza, Tanzania [52].

\section{References}

1. Rubin EJ, Baden LR, Morrissey S, Campion EW. Medical Journals and the 2019-nCoV Outbreak. N Engl J Med. 2020;382:866.

2. Reichmann JP. Letter to the Editor Re: Coronavirus disease 2019: The harms of exaggerated information and nonevidence-based measures. Eur J Clin Invest. 2020:e13224.

3. Brandt AM, Botelho A. Not a Perfect Storm - Covid-19 and Pages 5 of 7 
the Importance of Language. N Engl J Med. 2020;382:14931495.

4. https://finance.sina.cn/2019-12-13/detail-iihnzak1074832.d.html?from-wap)

5. http:/7news.ccty.com/2020/01/09/ARTIMxiGSCIHAjHAjC4B1Gy2VcP200109shtml?spm=C94212.P4YnMod.FiENPMkWvfnaiVY102.

6. Zhu N, Zhang D, Wang W, Li X, Yang B, et al. China Novel Coronavirus Investigating and Research Team. A Novel Coronavirus from Patients with Pneumonia in China, 2019. N Engl J Med. 2020;382:727-733.

7. Ren LL, Wang YM, Wu ZQ, Xiang ZC, Guo L, et al. Identification of a novel coronavirus causing severe pneumonia in human: a descriptive study. Chin Med J (Engl). 2020.

8. Menachery VD, Yount BL Jr, Debbink K, Agnihothram S, et al. A SARS-like cluster of circulating bat coronaviruses shows potential for human emergence. Nat Med. 2015;21:1508-13.

9. Ge XY, Li JL, Yang XL, Chmura AA, Zhu G, et al. Isolation and characterization of a bat SARS-like coronavirus that uses the ACE2 receptor. Nature. 2013;503:535-538.

10. Haby MM, Chapman E, Clark R, Barreto J, Reveiz L, et al. What are the best methodologies for rapid reviews of the research evidence for evidence-informed decision making in health policy and practice: a rapid review. Health Res Policy Syst. 2016;14:83.

11. Varker T, Forbes D, Dell L, Weston A, Merlin T, et al. Rapid evidence assessment: increasing the transparency of an emerging methodology. J Eval Clin Pract. 2015;21:1199-1204.

12. Chen N, Zhou M, Dong X, Qu J, Gong F, et al. Epidemiological and clinical characteristics of 99 cases of 2019 novel coronavirus pneumonia in Wuhan, China: a descriptive study. Lancet. 2020;395:507-513.

13. Siordia JA Jr. Epidemiology and clinical features of COVID-19: A review of current literature. J Clin Virol. 2020;127:104357.

14. Khan SA, Zia K, Ashraf S, Uddin R, Ul-Haq Z. Identification of chymotrypsin-like protease inhibitors of SARS-CoV-2 via integrated computational approach. J Biomol Struct Dyn. 2020;13:1-10.

15. Gordon CJ, Tchesnokov EP, Woolner E, Perry JK, Feng JY, et al. Remdesivir is a direct-acting antiviral that inhibits RNAdependent RNA polymerase from severe acute respiratory syndrome coronavirus 2 with high potency. J Biol Chem. 2020;pii: jbc.RA120.013679.

16. Shanmugaraj B, Siriwattananon K, Wangkanont K, Phoolcharoen W. Perspectives on monoclonal antibody therapy as potential therapeutic intervention for Coronavirus disease-19 (COVID-19). Asian Pac J Allergy Immunol. 2020;38:10-18.

17. Zhong L, Chuan J, Gong B, Shuai P, Zhou Y, Zhang Y, et al. Detection of serum IgM and IgG for COVID-19 diagnosis. Sci China Life Sci. 2020;63:777-780.

18. Duan K, Liu B, Li C, Zhang H, Yu T, et al. Effectiveness of convalescent plasma therapy in severe COVID-19 patients. Proc Natl Acad Sci U S A. 2020;117:9490-9496.

19. Zhou P, Yang XL, Wang XG, Hu B, Zhang L, et al. A pneumonia outbreak associated with a new coronavirus of probable bat origin. Nature. 2020;579:270-273.

20. Ji W, Wang W, Zhao X, Zai J, Li X. Cross-species transmission of the newly identified coronavirus 2019-nCoV. J Med Virol. 2020;92:433-440.

21. Li X, Zai J, Zhao Q, Nie Q, Li Y, et al. Evolutionary history, potential intermediate animal host, and cross-species analyses of SARS-CoV-2. J Med Virol. 2020.

22. Lei J, Li J, Li X, Qi X. CT Imaging of the 2019 Novel Coronavirus (2019-nCoV) Pneumonia. Radiology. 2020;295(1):18.

23. Rotzinger DC, Beigelman-Aubry C, von Garnier C, Qanadli SD. Pulmonary embolism in patients with COVID-19: Time to change the paradigm of computed tomography. Thromb Res. 2020;190:58-59.

24. Rubin GD, Ryerson CJ, Haramati LB, Sverzellati N, Kanne JP, RaoofS, et al. The Role of Chest Imaging in Patient Management during the COVID-19 Pandemic: A Multinational Consensus Statement from the Fleischner Society. Chest. 2020;pii :S0012-3692(20)30673-30675.

25. Sarma P, Kaur H, Kumar H, Mahendru D, Avti P, et al. Virological and Clinical Cure in Covid-19 Patients Treated with Hydroxychloroquine: A Systematic Review and MetaAnalysis. J Med Virol. 2020.

26. Gautret P, Lagier JC, Parola P, Hoang VT, Meddeb L, et al. Clinical and microbiological effect of a combination of hydroxychloroquine and azithromycin in 80 COVID-19 patients with at least a six-day follow up: A pilot observational study. Travel Med Infect Dis. 2020;101663.

27. Wang M, Cao R, Zhang L, Yang X, Liu J, et al. Remdesivir and chloroquine effectively inhibit the recently emerged novel coronavirus (2019-nCoV) in vitro. Cell Res. 2020;30:269-271.

28. Tu YF, Chien CS, Yarmishyn AA, Lin YY, Luo YH, et al. A Review of SARS-CoV-2 and the Ongoing Clinical Trials. Int J Mol Sci. 2020;21.pii:E2657.

29. Hirabayashi Y. Tocilizumab, an anti-interleukin-6 receptor antibody, efficiently ameliorates persistent joint inflammation in rheumatoid arthritis. Mod Rheumatol. 2020;28:1-22.

30. Tang N, Bai H, Chen X, Gong J, Li D, et al. Anticoagulant treatment is associated with decreased mortality in severe coronavirus disease 2019 patients with coagulopathy. J Thromb Haemost. 2020;18:1094-1099.

31. Xu H, Zhong L, Deng J, Peng J, Dan $\mathrm{H}$, et al. High expression of ACE2 receptor of 2019-nCoV on the epithelial cells of oral mucosa. Int J Oral Sci. 2020;12:8.

32. Chen L, Li X, Chen M, Feng Y, Xiong C. The ACE2 expression in human heart indicates new potential mechanism of heart injury among patients infected with SARS-CoV-2. Cardiovasc Res. 2020;116(6):1097-1100.

33. Varga Z, Flammer AJ, Steiger P, Haberecker M, Andermatt R, et al. Ebdothelial cell infection and endotheliitis in COVID-19. Lancet. 2020;395:1097-1100.

34. Su H, Yang M, Wan C, Tang F, Zhu HY, et al. Renal histopathological analysis of 26 post-mortem findings of patients with COVID-19 in China. Kidney Int. 2020.

35. Miller SE, Brealy JK. Response to "Visualization of putative coronavirus in Kidney". Kidney Int. 2020.

36. Tian S, Hu W, Niu L, Liu H, Xu H, Xiao SY. Pulmonary

Pages 6 of 7 
Pathology of Early-Phase 2019 Novel Coronavirus (COVID-19) Pneumonia in Two Patients With Lung Cancer. J Thorac Oncol. 2020;15:700-704.

37. Tian S, Xiong Y, Liu H, Niu L, Guo J, et al. Pathological study of the 2019 novel coronavirus disease (COVID-19) through postmortem core biopsies. Mod Pathol. 2020.

38. Karami P, Naghavi M, Feyzi A, Aghamohammadi M, Novin MS, et al. Mortality of a pregnant patient diagnosed with COVID-19: A case report with clinical, radiological, and histopathological findings. Travel Med Infect Dis. 2020.

39. Xu Z, Shi L, Wang Y, Zhang C, Liu S, et al. Pathological findings of COVID-10 associated with acute respiratory distress syndrome. Lancet Resp Med. 2020;8:420-422.

40. Barton LM, Duval EJ, Stroberg E, Ghosh S, Mukhopadhyay S. COVID-19 Autopsies, Oklahoma, USA. Am J Clin Pathol. 2020;pii:aqaa062.

41. Yao XH, Li TY, He ZC, Ping YF, Liu HW, et al. A pathological report of three COVID-19 cases by minimally invasive autopsies. Zhonghua Bing Li Xue Za Zhi. 2020;49(0):E009.

42. Decline of the necropsy. Editorial Br Med J. 1971;2:181-182.

43. Roberts WC. The autopsy: its decline and a suggestion for its revival. N Engl J Med. 1978;299:332-338.

44. Xu X, Barth RF, Buja LM. A Call to Action: The Need for Autopsies to Determine the Full Extent of Organ Involvement Associated With COVID-19. Chest. 2020. pii:S0012-3692(20)30687-5.

45. Russell B, Moss C, Rigg A, Hopkins C, Papa S, et al. Anosmia and ageusia are emerging as symptoms in patients with COVID-19: What does the current evidence say? E cancer medical science. 2020;14:ed98.

46. Sri Santosh T, Parmar R, Anand H, Srikanth K, Saritha M. A Review of Salivary Diagnostics and Its Potential Implication in Detection of Covid-19. Cureus. 2020;12:e7708.

47. Hanley B, Lucas SB, Youd E, Swift B, Osborn M. Autopsy in suspected COVID-19 cases. J Clin Pathol. 2020;73:239-242.

48. Yersin A. La peste bubonique in Hong-kong. Ann Inst Pasteur. 1894;8:862-867.

49. Morgagni JB- De sedibus et causis morborum per anatomen indagatis. Ex Typographia Remondiniana, Venetiis, 1761.

50. Callea F, Sergi C, Medicina D, Pizzorni S, Brisigotti M, et al. From immunohistochemistry to in situ hybridization. Liver. 1992;12:290-295.

51. Tad YD, Wald HL. The evolution of morbidity and mortality conferences BMJ Qual Saf. 2017;26:433-435.

52. Callea F. Microscopic and telescopic pathology. Digestive Liver Disease. 2017;49:1247. 